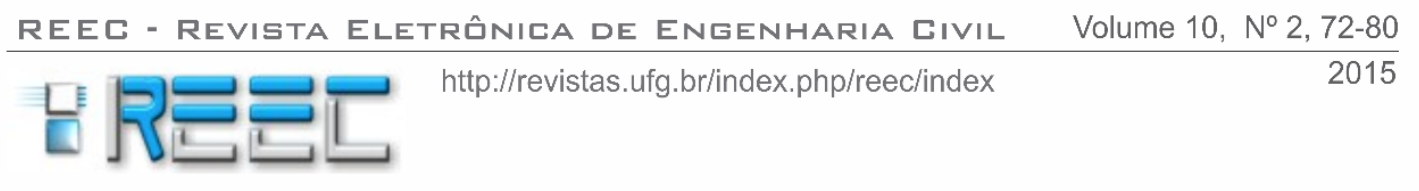

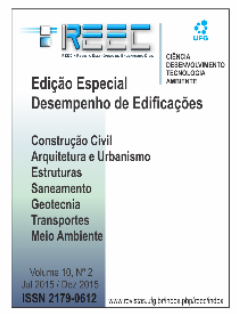

\title{
COMPARAÇÃO TEÓRICA E EXPERIMENTAL DA RESISTÊNCIA A FLEXÃO DE PERFIS METÁLICOS LAMINADOS E FORMADOS A FRIO
}

\section{Theoretical and experimental comparison of bending resistance in rolled steel profiles and cold-formed}

\author{
Murilo Bracht Malagutti ${ }^{1}$, Carlos Eduardo Nunes Torrescasana ${ }^{2}$, Roberto Carlos Pavan ${ }^{3}$
}

Recebido em 24 de julho de 2014; recebido para revisão em 03 de outubro de 2014; aceito em 30 de junho de 2015; disponível on-line em 23 de setembro de 2015.

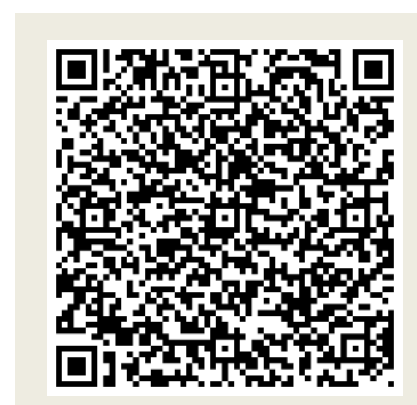

PALAVRAS CHAVE:

Estruturas metálicas;

Perfil l;

Flexão;

Vigas metálicas.

\section{KEYWORDS:}

Steel structures;

Profile I;

Bending;

Steel beams.

\footnotetext{
* Contato com os autores:

${ }^{1}$ e-mail: murilo_107@unochapeco.edu.br ( M. B. Malagutti )

Acadêmico do curso Engenharia Civil da Universidade Comunitária da Região de Chapecó (Unochapecó).

${ }^{2}$ e-mail : ctorres@unochapeco.edu.br (C. E. N. Torrescasana )

Eng. Civil, M.Sc. Professor do curso de Eng. Civil da Universidade Comunitária da Região de Chapecó (Unochapecó).

${ }^{3}$ e-mail : pavan.uffs@uffs.edu.br (R. C. Pavan)

Prof. Dr. do curso de Eng. Ambiental da Universidade da Fronteira Sul (UFFS).
} vigas submetidas à flexão. Foram comparados três modelos de perfis metálicos, sendo eles: formado a frio e soldado, tipo viga soldada e laminado. Foram confeccionados quatro corpos de prova de cada modelo, sendo estes todos com comprimento de $1500 \mathrm{~mm}$, simulando perfis comumente usados na confecção de vigas de estruturas metálicas. Todos os corpos de prova foram ensaiados em laboratório, utilizando-se um pórtico de cargas para aplicar uma carga pontual no centro do vão. A carga foi aumentada gradativamente, e a cada intervalo tomou-se nota da deformação vertical no centro do perfil. Ao final do ensaio, foram analisados os resultados de resistência de cada modelo de perfil e seus custos comparados. Conclui-se que os perfis confeccionados em aço laminado apresentam a melhor eficiência na resistência à carga e também menor custo por metro de viga, proporcionado uma economia aproximada de $20 \%$ em relação aos outros modelos estudados.

ABSTRACT: This study aimed to find the profile "I" with better efficiency for beams subjected to bending. Three models of steel profiles were compared, namely: cold-formed and welded, welded beam type and laminate. They were made four specimens of each model, all with length of $1500 \mathrm{~mm}$, simulating profiles commonly used in the manufacture of steel beams. All samples were tested in the laboratory, using a frame loads to apply a point load in the center of the span. The load was gradually increased, and the vertical deflection at the center of the profile, recorded every interval. At the end of the test, the strength results of each profile model and their costs were analyzed. We conclude that the laminate steel profiles have highest efficiency considering the applied load and also lower cost per meter of beam, providing an approximate saving of $20 \%$ compared to other studied models. 


\section{INTRODUÇÃO}

Com o avanço da construção civil, percebe-se uma crescente necessidade na utilização e no domínio de técnicas construtivas de maior rendimento e qualidade. Em destaque estão as estruturas metálicas, como elementos prémoldados que garantem eficiência e precisão na execução da obra.

De acordo com Pfeil e Pfeil (2011): “O primeiro material siderúrgico empregado na construção foi o ferro fundido. Entre 1780 e 1820 construíram-se pontes em arco ou treliçadas, com elementos em ferro fundido trabalhando em compressão".

$O$ início da utilização do metal na construção civil iniciou-se em fins do século XVIII, basicamente em pontes pênseis, conforme afirma Pfeil (1982).

Vieira (2010) divide os perfis de aço estrutural em três grupos: (1) perfis laminados a quente, (2) perfis formados por soldagem de chapas, e (3) perfis compostos por chapas dobradas ou perfiladas, conhecidos como perfis formados a frio.

Faé (2010), em seu estudo comparativo de custos entre estruturas metálicas e de concreto armado, afirma que o valor superior da estrutura de aço é justificado pelo elevado valor de matéria prima, e seu custo de fabricação, montagem e tratamento de superfície, os quais exigem profissionais qualificados para os serviços.

De acordo com pesquisa desenvolvida pelo CBCA (2003), "Atualmente já se coloca em confronto os fatores que apontam para uma ou outra solução de construção - em concreto ou em aço - de forma que na decisão final têm pesado significativamente fatores como: rapidez de montagem e economia de fundações que elegem a solução metálica como mais vantajosa"

Ferreira, (2007) cita que, de acordo com informações fornecidas pelo CBCA, o consumo de aço na construção civil no Brasil, é de cerca de 5,0 kg por habitante. Comparando com a Inglaterra, que é de $20 \mathrm{~kg} / \mathrm{hab}$ e Estados Unidos que é de $30 \mathrm{~kg} / \mathrm{hab}$, pode-se acreditar no potencial de crescimento deste mercado no nosso país.

Este trabalho pretende definir o perfil "I" com melhor eficiência para vigas submetidas á flexão. Foram analisadas vigas em perfil laminado, perfil moldado a frio e soldado, obtendo o formato "I" com dois perfis de formato " $\mathrm{U}$ " unidos por solda através de suas bases, e também por perfil "I" do tipo viga soldada obtido por meio da união soldada de três chapas que formam mesas e alma.

Atualmente verifica-se a predominância do uso de perfis moldados a frio na confecção de estruturas metálicas, porém, almeja-se concluir, se realmente o sistema utilizado pela grande maioria das empresas é o de melhor custo/benefício.

\section{ESTRUTURAS METÁLICAS}

\subsection{PERFIS METÁLICOS EM FORMATO “I"}

De acordo com Juvandes (2002), o objetivo da utilização de perfis de formato "I" está principalmente em afastar a concentração da área de aço da linha neutra, minimizando assim o valor das tensões normais, decorrentes do momento fletor. Porém, tem-se como consequência, tensões tangenciais elevadas na alma, na altura da linha neutra, devido a dimensão " $\mathrm{t}_{\mathrm{a}}$ " da nervura aparecer no denominador da equação de Jourawski (ou seja, nos pontos da viga onde a tensão normal é máxima - arestas superior e inferior, a tensão tangencial é nula, enquanto na linha neutra, onde $\sigma$ é igual a zero, a tensão $\tau$ atinge valor extremo), conforme pode-se ver na Figura 1. A descontinuidade do valor da tensão na transição entre a mesa e a alma acontece devido à mudança da largura da seção nesses locais.

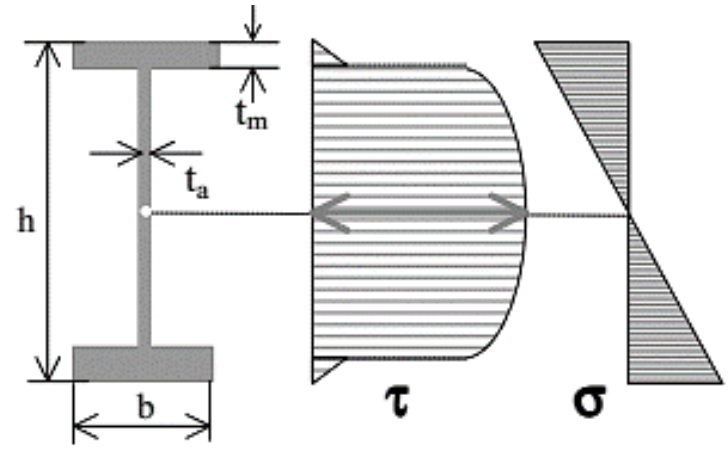

FIGURA 1: Tensões no perfil "I". 
Dias (2000) afirma que os perfis do tipo "I", tanto laminados como formados á frio, são os mais utilizados na confecção de vigas, devido a sua forma de seção, são adequados para resistir os esforços de compressão e tração por intermédio das mesas, que normalmente são mais espessas que a alma.

Santos, (2000) em sua pesquisa com perfis de formato " $\mathrm{I}$ ", verificou que os critérios de dimensionamento de estruturas conforme a NBR 8800 (ABNT, 2008) proporcionam grande índice de confiabilidade.

Conforme recomenda Andrade (2012), "Nas seções com alma e mesa esbeltas, o momento resistente é calculado com fórmulas que consideram interação das flambagens locais das duas chapas. As fórmulas para dimensionamento podem ser encontradas no Anexo $\mathrm{H}$ da norma NBR 8800 (ABNT, 2008)".

\subsubsection{PERFIS METÁLICOS LAMINADOS EM FORMATO "I"}

Conforme comentado por Vieira (2010) "Os perfis laminados apresentam uma grande capacidade portante, e juntamente com ela uma grande relação massa/resistência". Seguindo, comenta sobre o alto custo desse material, o que torna a aplicação desse material como estrutura, inviável em grande parte dos empreendimentos.

A NBR 8800 (ABNT, 2008) recomenda:

"Antes do seu uso na fabricação, os materiais laminados devem estar desempenados dentro das tolerâncias de fornecimento. Caso essas tolerâncias não estejam sendo atendidas, é permitido executar trabalho corretivo pelo uso de aquecimento controlado e/ou desempeno mecânico, sujeito a limitação de 12.2.1.1.2. Aquecimento e meios mecânicos são também permitidos para se obter as pré-deformações desejadas."

Conforme Pfeil (1982), "Os perfis "I" laminados no Brasil pela Companhia Siderúrgica Nacional seguem os padrões americanos, sendo produzidos com diferentes alturas. Para cada altura, fabricam-se perfis com pesos diferentes, obtidos aumentando-se a espessura da alma, sem alterar a altura total".

Já segundo Dias (2000), os perfis metálicos laminados produzidos no Brasil apresentam pouca disponibilidade de dimensões e produção, sendo mais facilmente encontrados e com maiores alternativas, os perfis importados, comercializados em barras de 6000 e 12000 mm.

\subsubsection{PERFIS METÁLICOS MOLDADOS Á FRIO E SOLDADOS EM FORMATO "I"}

É pratica comum entre os fabricantes de estruturas metálicas, fabricação de vigas por meio da composição de barras chatas unidas por cantoneiras, parafusos, rebites e soldagem. Estes perfis funcionam como se fossem inteiriços, podendo-se calcular os esforços nos elementos de união computando as tensões médias nas faces que estão sendo unidas, conforme recomenda a NBR 14762 (ABNT, 2001).

Pfeil (1982) afirma que é possível construir perfis semelhantes aos laminados fazendo o uso de chapas dobradas, unindo perfis dobrados a frio do tipo cantoneira ou $\mathrm{U}$.

Vieira (2010) fala em sua pesquisa sobre a grande quantidade de mão-de-obra envolvida no processo de produção de perfis soldados, que apesar de sua facilidade de obtenção de perfis de diversos tamanhos, seu custo final fica elevado. Dessa forma, os perfis formados a frio ganham cada vez mais espaço no mercado, pela facilidade de produção e do menor custo em relação aos mesmos perfis obtidos por outros métodos construtivos.

Pinheiro (2005) ainda aconselha: "Para um maior controle de qualidade das ligações soldadas deve-se, quando possível, utilizá-las apenas na fábrica, onde se têm melhores mecanismos de controle e utilizar em campo (na obra) apenas ligações parafusadas".

Conforme explicado por Silva (2006), perfis formados a frio são produzidos por dobramento de chapas de aço em temperatura ambiente, cujo processo pode ser descontínuo, feito por prensa dobradeira/viradeira, ou continuo, com o uso de perfiladeiras. 
Em sua pesquisa, Silva (2006) compara os perfis formados a frio com os laminados: "Em geral, apresentam uma maior relação inércia/peso que os laminados, resultando em menor consumo de material, reduzindo o custo final do produto.

Segundo Guimarães et al (2010), a utilização de perfis formados a frio no Brasil fez com que seu uso fosse disseminado em diferentes tipos de obra, inclusive como sistemas estruturais mistos. "Os PFFs são usados principalmente nas construções de pequeno porte e conjuntos habitacionais, isso graças à sua grande versatilidade, leveza, facilidade de fabricação e execução."

\section{PROCEDIMENTOS METODOLÓGICOS}

Este estudo foi realizado com base em vigas confeccionadas em diferentes tipos de perfis metálicos, submetidos à flexão. Inicialmente foi escolhido um perfil laminado e, a partir da carga resistida por ele, foi procedido o dimensionamento dos demais perfis. Após a confecção de quatro peças de cada modelo, estas foram ensaiadas à flexão no pórtico de cargas do laboratório de engenharia civil da UNOCHAPECO, e seus custos de produção comparados.

\subsection{DIMENSIONAMENTO DOS PERFIS}

\subsubsection{Perfil laminado}

Inicialmente foi necessário levar em consideração a capacidade máxima do pórtico de cargas, estimada em 100 toneladas; portanto foi escolhido um perfil que resista a cargas abaixo deste limite. Foi preciso, também, levar em consideração a operação e manuseio das peças, necessárias durante a execução dos ensaios.

Foi considerada a disponibilidade de perfis laminados em formato "I" comercializados em nossa região. Com base nestes dados, optou-se pelo perfil laminado modelo "I" $200 \mathrm{~mm} \mathrm{x}$ $19,3 \mathrm{~kg} / \mathrm{m}$, tendo peso de 19,3 kg por metro linear, facilitando as operações de ensaio em laboratório e a confecção de perfis semelhantes.

A carga de ensaio foi aplicada no centro da viga, com comprimento de $1505 \mathrm{~mm}$, com extremidades simplesmente apoiadas sobre peças redondas de aço laminado.

\subsubsection{Dimensionamento do perfil "I" laminado}

Para definição da carga que o perfil "I" laminado $200 \mathrm{~mm} \times 19,3 \mathrm{~kg} / \mathrm{m}$ resiste, foram utilizados os procedimentos descritos na NBR 8800 (ABNT, 2008) e suas verificações pertinentes. O limite de deformação foi estabelecido por meio do cálculo da flecha máxima admissível para a viga. As propriedades deste modelo de perfil, utilizadas para o dimensionamento e verificações, são fornecidas pelo fabricante do material.

\subsubsection{Carga resistida pelo perfil "I" laminado}

Para o dimensionamento, a viga foi considerada biapoiada com carga pontual aplicada ao centro da peça. Portanto, tem-se o momento por meio da Equação 1:

$$
\mathrm{M}=\frac{\mathrm{P} \cdot \mathrm{L}}{4}
$$

Em que:

M: Momento fletor (kgf.cm);

P : carga pontual aplicada (kgf);

L: vão da viga $(\mathrm{cm})$.

Por meio deste dimensionamento verificou-se a carga de flexão limite $P$, que gera a tensão de escoamento $f_{y}$. Verificou-se que o perfil "I" laminado resiste a uma carga de $12.700 \mathrm{~kg}$. Para o critério de cálculo utilizado, admitiu-se a viga com seção compacta, no estado limite plástico; isto justifica a colocação de enrijecedores no centro da viga para evitar a flambagem lateral com torção da viga.

\subsubsection{Flecha máxima admitida para o perfil "I"} laminado

Por meio das recomendações da NBR 8800 (ABNT,2008), para sobrecargas em vigas, a flecha máxima recomendada é $L / 360$, ou seja, 4,2 mm, e são necessários $20.000 \mathrm{~kg}$ de carga no centro da viga para atingir esta deformação.

\subsubsection{Dimensionamento de perfil "I" formado a frio e soldado}

O perfil "I" formado a frio, é composto 
de dois perfis " $U$ ", com bases soldadas entre si, conforme se pode ver na Figura 2 e legendas conforme Tabela 1. O dimensionamento dos perfis seguiu os critérios da NBR 14762 (ABNT, 2001) e suas verificações assim como a solda de ligação, que deve resistir a mesma carga do perfil "I" laminado $200 \mathrm{~mm} \times 19,3 \mathrm{~kg} / \mathrm{m}$. O limite de deformação foi calculado por meio da flecha máxima admissível para a viga.

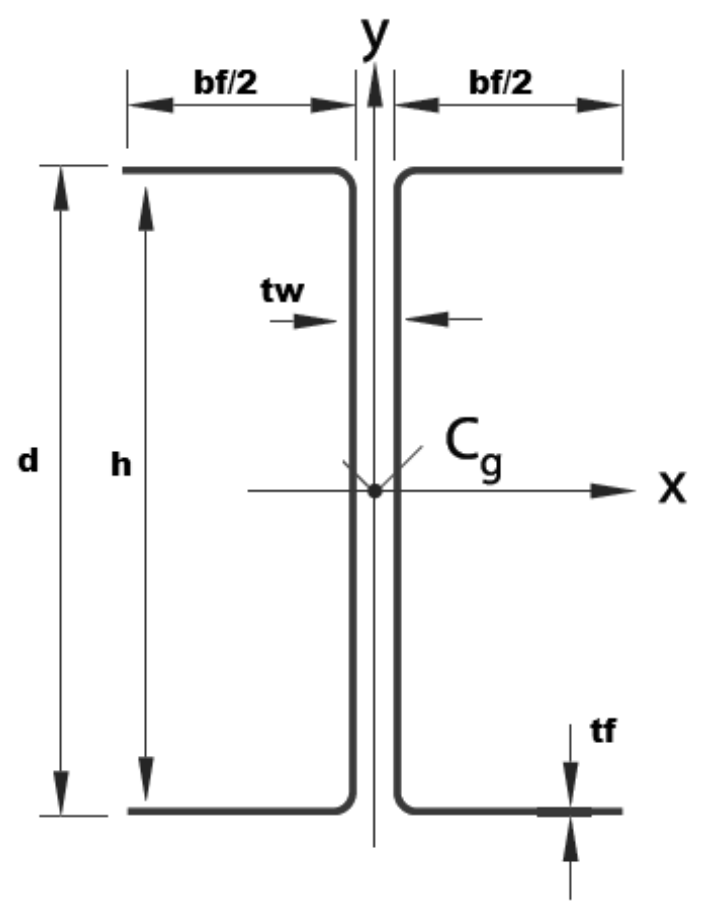

FIGURA 2: Perfil "I" moldado a frio e soldado.
3.1.3.1 Propriedades do perfil "I" formado a frio e soldado

Como o principal objetivo deste estudo é a comparação de custos entre os modelos de perfis, o dimensionamento do perfil I formado a frio e soldado iniciou com a aproximação do peso e de aço por metro linear de viga. Para alcançar um peso aproximado de $19 \mathrm{Kg} / \mathrm{m}$, precisamos que cada peça " $U$ " que formará a viga não ultrapasse os $9,5 \mathrm{Kg} / \mathrm{m}$. É importante que o perfil se assemelhe aos demais em suas dimensões de alma e mesa.

Primeiramente optou-se pelo perfil " $U$ " com medidas de base de $200 \mathrm{~mm}$ e abas de $60 \mathrm{~mm}$ (externos) em chapa de $3,8 \mathrm{~mm}$ de espessura. Tem-se então: área de aço do perfil "U": 0,3124 $\mathrm{m}^{2} / \mathrm{m}$; peso da chapa de aço carbono $3,80 \mathrm{~mm}$ : $30,5 \mathrm{Kg} / \mathrm{m}^{2}$; peso por metro de perfil " $\mathrm{U}$ ": 9,53 $\mathrm{Kg} / \mathrm{m}$; Considerando a composição de duas peças "U" tem-se 19,06 Kg/m de perfil composto.

3.1.3.2 Cálculo das propriedades do perfil "I" composto

Segundo SOARES (2008), calculou-se as propriedades do perfil "I" composto (Figura 2) para o dimensionamento inicial. Estas são dispostas na Tabela 1.

TABELA 1: Propriedades perfil "I" composto - dimensionamento inicial.

PROPRIEDADES PERFIL "I" COMPOSTO

\begin{tabular}{cccccccccc}
\hline $\begin{array}{c}\text { Massa Linear } \\
(\mathrm{Kg} / \mathrm{m})\end{array}$ & $\begin{array}{c}\mathrm{d} \\
(\mathrm{mm})\end{array}$ & $\begin{array}{c}\mathrm{bf} \\
(\mathrm{mm})\end{array}$ & $\begin{array}{c}\mathrm{tw} \\
(\mathrm{mm})\end{array}$ & $\begin{array}{c}\mathrm{tf} \\
(\mathrm{mm})\end{array}$ & $\begin{array}{c}\mathrm{h} \\
(\mathrm{mm})\end{array}$ & $\begin{array}{c}\text { Área } \\
\left(\mathrm{cm}^{2}\right)\end{array}$ & $\begin{array}{c}\mathrm{Zx} \\
\left(\mathrm{cm}^{3}\right)\end{array}$ & $\begin{array}{c}\mathrm{ly} \\
\left(\mathrm{cm}^{4}\right)\end{array}$ & $\begin{array}{c}\mathrm{ry} \\
(\mathrm{cm})\end{array}$ \\
\hline $\mathbf{1 9 , 0 6}$ & 200 & 120 & 7,6 & 3,8 & 192 & 23,8 & 159,8 & 110,14 & 2,177 \\
\hline
\end{tabular}


3.1.3.3 Carga resistida pelo perfil "I" formado a frio e soldado

Para os cálculos de dimensionamento, a viga foi considerada biapoiada com carga pontual aplicada no centro da peça; portanto tem-se o momento por meio da Equação 1. Por meio deste dimensionamento verificou-se que o perfil " $\mathrm{I}$ " laminado resiste a uma carga de $10.666 \mathrm{~kg}$. Devido à esbeltez da mesa, ocorreu flambagem localizada neste modelo. Para solucionar este problema, optou-se por enrijecer as abas (mesa) do perfil, ficando a dobra do perfil " $U$ " (Figura 3), aliada a colocação dos enrijecedores no centro da viga.

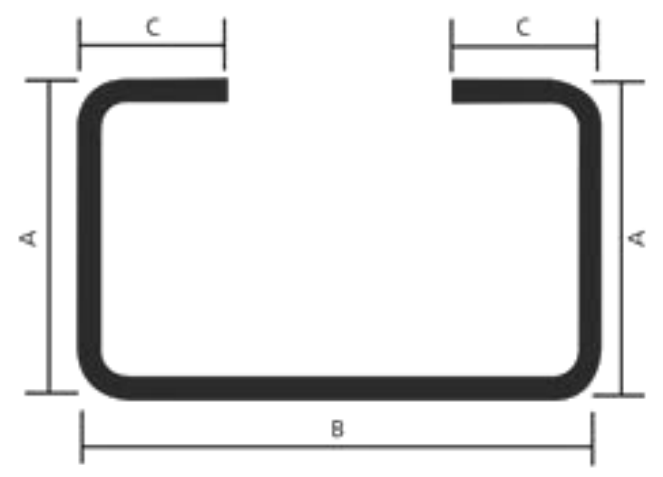

FIGURA 3: Perfil “U” enrijecido.

Ao final das verificações, temos as novas propriedades do perfil "I" composto, recalculadas após as alterações, dispostas na Tabela 2. Nesta situação o laminado resiste a uma carga de $8.666 \mathrm{~kg}$.

\subsubsection{Flecha máxima recomendada para o perfil} "I" formado a frio e soldado

Pelas recomendações, verificou-se que a flecha máxima recomendada é de $4,2 \mathrm{~mm}$, e são necessários $13.470 \mathrm{~kg}$ de carga no centro da viga para atingir esta deformação.

\subsubsection{Dimensionamento de perfil "I" tipo viga soldada (VS)}

Perfil do tipo VS é formado pela união de três chapas cortadas separadamente, unidas por filamento de solda, formando mesas e alma. A VS utilizada foi dimensionada de acordo com a NBR 8800 (ABNT,2008) e suas verificações, e deve resistir a mesma carga do perfil "I" laminado 200x19,3. O limite de deformação foi calculado por meio da flecha máxima admissível para a viga. As propriedades do perfil "I" tipo VS adotadas seguem o informado em PINHEIRO (2005).

\subsubsection{Carga resistida pelo perfil "I" tipo viga soldada (VS) \\ Para o dimensionamento a viga foi} considerada biapoiada com carga pontual aplicada exatamente ao centro da peça; portanto tem-se o momento por meio da Equação 1, apresentada anteriormente.

Por meio deste dimensionamento verificou-se que o perfil "I" soldado resiste a uma carga de $12.533 \mathrm{~kg}$. Verificou-se, também, a necessidade de colocação de enrijecedores no centro da viga para evitar a flambagem da mesa.

TABELA 2 : Propriedades perfil "I" composto - dimensionamento final.

PROPRIEDADES PERFIL "I" COMPOSTO - DEFINITIVO

\begin{tabular}{cccccccccc}
\hline $\begin{array}{c}\text { Massa Linear } \\
(\mathrm{Kg} / \mathrm{m})\end{array}$ & $\begin{array}{c}\mathrm{d} \\
(\mathrm{mm})\end{array}$ & $\begin{array}{c}\mathrm{bf} \\
(\mathrm{mm})\end{array}$ & $\begin{array}{c}\mathrm{tw} \\
(\mathrm{mm})\end{array}$ & $\begin{array}{c}\mathrm{tf} \\
(\mathrm{mm})\end{array}$ & $\begin{array}{c}\mathrm{h} \\
(\mathrm{mm})\end{array}$ & $\begin{array}{c}\text { Área } \\
\left(\mathrm{cm}^{2}\right)\end{array}$ & $\begin{array}{c}\mathrm{Zx} \\
\left(\mathrm{cm}^{3}\right)\end{array}$ & $\begin{array}{c}\text { ly } \\
\left(\mathrm{cm}^{4}\right)\end{array}$ & $\begin{array}{c}\mathrm{ry} \\
(\mathrm{cm})\end{array}$ \\
\hline 19,06 & 200 & 80 & 7,6 & 3,8 & 192 & 23,8 & 129,97 & 68,9 & 1,721 \\
\hline
\end{tabular}


3.1.4.2 Flecha máxima recomendada para o perfil "I" tipo viga soldada (VS)

Por meio das recomendações, verificouse que a flecha máxima recomendada é de 4,2 mm, e são necessários $20.560 \mathrm{~kg}$ de carga no centro da viga para atingir esta deformação.

\subsubsection{Ensaio}

O ensaio foi realizado, no pórtico de cargas, para as diferentes formas de vigas, centralizando o ponto de aplicação de carga no centro do vão da viga. Fixou-se um extensômetro, medindo a deformação no centro da viga. Aplicouse carga pelo pórtico de cargas até que as vigas atingiram sua flecha máxima admissível.

\section{RESULTADOS}

\subsection{RESULTADOS DOS ENSAIOS}

Com a aplicação da carga, foram anotadas as deformações verticais da viga, nos quatro corpos de prova. A Figura 4 apresenta os gráficos da resistência média entre os quatro corpos de prova ensaiados, para cada tipo de perfil.

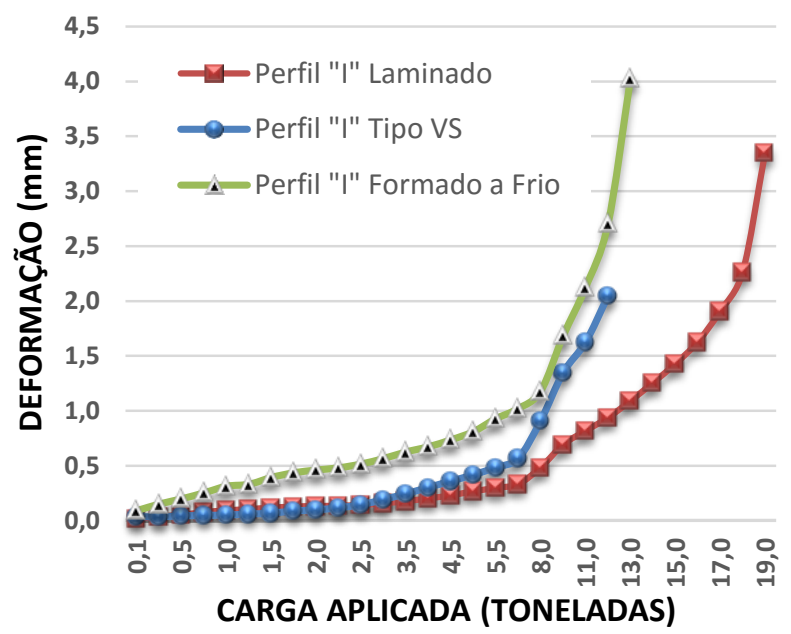

FIGURA 4: Comparação entre Carga Aplicada x Deformação.

Foi observado que a capacidade de carga na flexão resultou em valores menores que a carga relacionada à flecha máxima permitida, de
4,2 mm; isto justifica a ocorrência de flambagem lateral com torção, conforme pode ser visto na Figura 5. Cabe salientar que ao atingir a carga limite de flexão, a flecha esperada seria de 2 a $3 \mathrm{~mm}$.

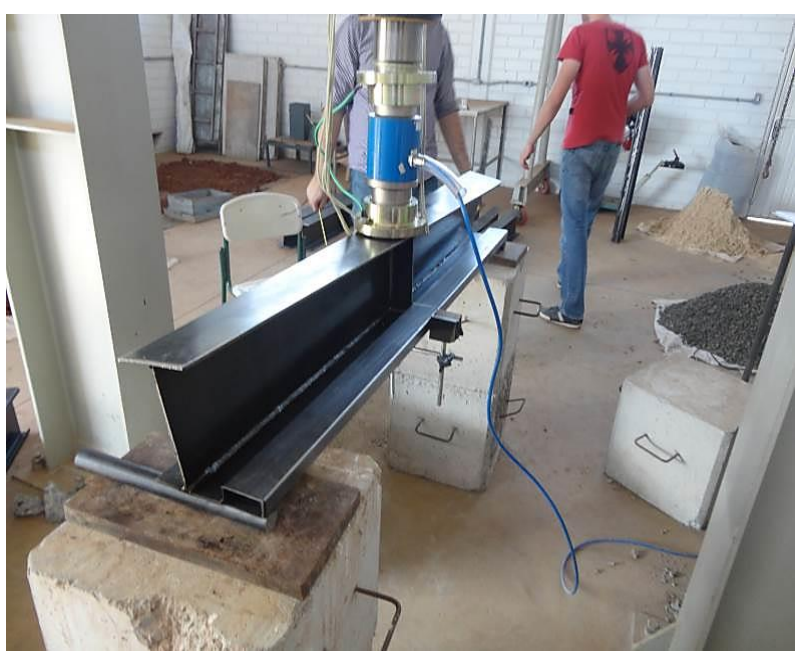

FIGURA 5: Flambagem lateral com torção - Perfil "I" tipo viga soldada.

Conforme o gráfico da Figura 4, percebe-se que o perfil formado a frio atingiu uma flecha de 4,2 $\mathrm{mm}$ com uma carga aproximada de $13.000 \mathrm{~kg}$, ou seja, ultrapassando a carga permitida para a flexão. O perfil laminado atingiu uma flecha pouco inferior a 3,5 $\mathrm{mm}$, com uma carga aproximada de $18.000 \mathrm{~kg}$, também, superior a sua carga máxima de flexão. Por último, a viga VS atingiu uma flecha pouco maior de $2 \mathrm{~mm}$ para uma carga de flexão aproximada de $12.000 \mathrm{~kg}$. Dos três perfis estudados, o perfil VS foi o que apresentou o comportamento no ensaio mais próximo do cálculo teórico de momento fletor e flecha.

O gráfico da Figura 6, demonstra a carga à flexão do perfil em relação a carga aplicada no centro do vão. A carga teórica é calculada conforme a norma estabelece, e passa por todas as verificações necessárias. A carga sem os coeficientes de segurança ignora o coeficiente de majoração de carga e o coeficiente de minoração de resistência do aço. A carga do ensaio é demonstrada pelo valor médio entre os quatro corpos de prova ensaiados. 


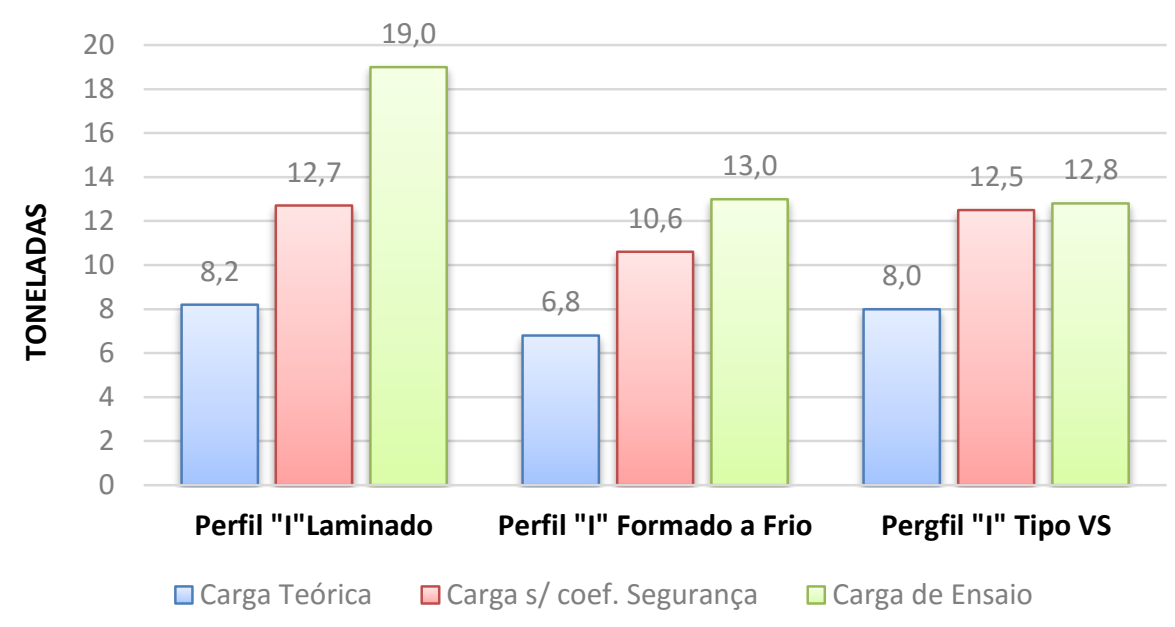

FIGURA 6: Gráfico comparativo - Cargas (toneladas) dos perfis "I".

\subsection{COMPARATIVO DE CUSTOS}

Para efeito de custo, é necessário analisar todas as despesas envolvidas até a obtenção do perfil final, conforme os modelos ensaiados. As metalúrgicas da região oeste de Santa Catarina determinam os valores dos serviços de estruturas metálicas por quilograma de material processado. Para este estudo, foram solicitados orçamentos a duas empresas da região especializadas em estruturas metálicas, para a confecção dos 12 corpos de prova. Por meio destes orçamentos, calculou-se a média do valor de serviço por kg de estrutura. O valor da compra das chapas e perfis de aço carbono foi extraído das notas fiscais de compra deste material pela metalúrgica que executou o serviço. A Tabela 3 demonstra o custo de cada modelo de perfil estudado, exceção ao perfil "I" laminado que foi utilizado conforme fornecido pela indústria.

Conclui-se que, ao dimensionar e executar projetos em estrutura metálica, sempre que possível utilizando perfis de aço laminado, estes proporcionarão uma economia de aproximadamente $20 \%$ em relação aos perfis formados á frio e soldados. O modelo tipo viga soldada tornou-se ainda mais oneroso, tendo seu custo em torno de $33 \%$ mais alto que o formado a frio e soldado.

\begin{tabular}{|c|c|c|c|c|c|}
\hline \multicolumn{2}{|r|}{ Perfil "I" Laminado } & \multirow{2}{*}{$\begin{array}{c}\text { Quant. } \\
6,00\end{array}$} & \multirow{2}{*}{$\frac{\text { Unid. }}{\mathrm{m}}$} & \multirow{2}{*}{$\begin{array}{c}\text { R\$ Unit. } \\
69,67\end{array}$} & \multirow{2}{*}{$\begin{array}{c}\text { R\$ Total } \\
418,00\end{array}$} \\
\hline Material & Viga "I" Estr A572 200mmx19,3kg/m & & & & \\
\hline Mão-de-Obra & Dispensável & - & - & - & - \\
\hline \multicolumn{2}{|c|}{ Custo Total - Corpos de Prova } & - & - & - & 418,00 \\
\hline \multicolumn{2}{|c|}{ Custo por metro de perfil/viga } & - & - & - & 69,67 \\
\hline \multicolumn{2}{|c|}{ Perfil "I" Formado a Frio e Soldado } & Quant. & Unid. & R\$ Unit. & R\$ Total \\
\hline Material & Chapa $1200 \times 3000 \times 3,75 \mathrm{~mm}$ & 108,67 & $\mathrm{~kg}$ & 3,00 & 326,00 \\
\hline \multirow[t]{2}{*}{ Mão-de-Obra } & Corte e Dobra & Incluso & - & - & - \\
\hline & Montagem, Solda e Acabamento & 108,67 & $\mathrm{~kg}$ & 1,75 & 190,15 \\
\hline \multicolumn{2}{|c|}{ Custo Total - Corpos de Prova } & - & - & - & 516,15 \\
\hline \multicolumn{2}{|c|}{ Custo por metro de perfil/viga } & - & - & - & 86,03 \\
\hline \multicolumn{2}{|r|}{ Perfil "I" Tipo Viga Soldada } & Quant. & Unid. & R\$ Unit. & $\mathbf{R} \$$ Total \\
\hline \multirow[t]{2}{*}{ Material } & Chapa $1200 \times 3000 \times 4,75 \mathrm{~mm}$ & 70 & 210 & - & 210,00 \\
\hline & Chapa $1200 \times 3000 \times 6,30 \mathrm{~mm}$ & 75 & 225 & - & 225,00 \\
\hline \multirow[t]{2}{*}{ Mão-de-Obra } & Corte e Dobra & Incluso & - & - & - \\
\hline & Montagem, Solda e Acabamento & 145 & - & - & 253,75 \\
\hline \multicolumn{2}{|c|}{ Custo Total - Corpos de Prova } & & & & 688,75 \\
\hline \multicolumn{2}{|c|}{ Custo por metro de perfil/viga } & & & & 114,79 \\
\hline
\end{tabular}




\section{CONCLUSÃO}

Ao final deste trabalho, conclui-se que o perfil "I" de aço laminado apresenta vantagens em relação aos demais nos quesitos analisados: resistência à flexão, menor flecha e menor custo final. Devido este tipo de perfil ser produzido em grandes siderúrgicas, em processo automatizado, com rigoroso controle de qualidade, percebe-se o excelente desempenho da peça, apresentando perfeição em suas dimensões e excelente acabamento.

A utilização de enrijecedores nas extremidades das vigas pode contribuir para evitar o efeito de flambagem lateral com torção, podendo ser uma alternativa para analisar as deformações verticais das peças.

Por fim, este trabalho busca contribuir no sentido de orientar a escolha da tipologia de perfil "I" mais eficiente e, desta forma, reduzir o custo da estrutura, para os casos onde o carregamento concentrado é a principal carga atuante no perfil.

\section{AGRADECIMENTOS}

Os autores agradecem o suporte da Unochapecó - Universidade Comunitária da Região de Chapecó.

\section{REFERÊNCIAS BIBLIOGRÁFICAS}

ASSOCIAÇÃO BRASILEIRA DE NORMAS TÉCNICAS, NBR 14762: Dimensionamento de estruturas de aço constituídas por perfis formados a frio - Procedimento. Rio de Janeiro, 2001.

ASSOCIAÇÃO BRASILEIRA DE NORMAS TÉCNICAS, NBR 8800: Projeto e execução de estruturas de aço em edifícios. Rio de Janeiro, 2008.

ANDRADE, W. Estruturas de Aço. 2012. Disponível em: < http://www.engcivilufgcac.com.br/2012/pgs/down _arqs.php>. Acesso em: 28 abril de 2012.

CENTRO BRASILEIRO DA CONSTRUÇÃO EM AÇO. Bibliografia técnica para o desenvolvimento da construção metálica: Volume - IV - Edifícios de pequeno porte estruturados em aço. Rio de Janeiro, 2003.
DIAS, L. A.M. Estruturas de aço: Conceitos, Técnicas e Linguagem. 3a Ed. São Paulo: Zigurate Editora, 2000.

FAÉ, R. Análise Estudo comparativo de custos da estrutura resistente de um edifício construído em dois métodos construtivos: em aço e concreto armado convencional. 2010. 63 f. Trabalho de conclusão de curso - Universidade Comunitária da Região de Chapecó - UNOCHAPECO, 2010.

FERREIRA, A. C. Vigas metálicas protendidas: análise estática, modal e de ruptura do cabo de protensão e aplicativo computacional para projetos. 2007. $276 \mathrm{f}$. Dissertação de mestrado - Universidade de Brasília, 2007.

GUIMARÃES, F. S. et al. Análise experimental de vigas mistas de aço e concreto com perfil de aço formado a frio. 2010. 63 f. Trabalho de conclusão de curso Universidade Vale do Rio Doce, 2010.

JUVANDES, L. F. P. Tensões Tangenciais em Flexão e Torção. 2002. Disponível em: < http://paginas.fe.u'p.pt/ juvandes/RM2/tensaotangencial.pdf>. Acesso em: 25 de abril de 2012.

PFEIL, W. Estruturas de aço. 3a Ed. Rio de Janeiro: LTCLivros Técnicos e Científicos Editora S.A., 1982.

PFEIL, W.; PFEIL, M. Estruturas de aço: dimensionamento prático de acordo com a NBR 8800:2008. 8o Ed. Rio de Janeiro: LTC - Livros Técnicos e Científicos Editora S.A., 2011.

PINHEIRO, A. F. B. Estruturas metálicas: cálculos, detalhes, exercícios e projetos. 2a Ed. São Paulo: Blucher, 2005.

SANTOS, L. L. Sobre a confiabilidade na flexão de vigas segundo as normas de estruturas metálicas. 2000. 156 f. Dissertação de mestrado - Universidade Federal do Rio Grande do Sul, 2000.

SILVA, A. C. Estudo de ligações parafusadas em perfis formados a frio. 2006. 156 f. Dissertação - (PósGraduação) - Universidade Federal de Ouro Preto, 2006.

SOARES, Marco. Seções Planas 120. 2008. Disponível em: < http://www.mspc.eng.br/matr/secplan120.shtml >. Acesso em: 15 de setembro de 2012.

VIEIRA, G. S. Análise experimental de vigas de seção "I" compostas de perfis formados a frio com emendas soldadas, submetidas à flexão simples. 2010. $134 \mathrm{f}$. Dissertação de mestrado - Universidade Federal de Goiás, 2010. 